\title{
Laparoscopic sleeve gastrectomy in obese patients with ventricular assist devices: a data note
}

\author{
Adrian daSilva-deAbreu ${ }^{1,2,3^{*}}$ (D), Kiran Garikapati ${ }^{1}$, Bader Aldeen Alhafez ${ }^{4}$, Sapna Desai ${ }^{1,2}$, Clement Eiswirth $^{1,2}$, \\ Selim Krim ${ }^{1,2}$, Hamang Patel ${ }^{1,2}$, Carl J. Lavie ${ }^{1,2}$, Hector O. Ventura ${ }^{1,2}$, Juan Francisco Loro-Ferrer ${ }^{3}$ \\ and Stacy A. Mandras ${ }^{1,2}$
}

\begin{abstract}
Objectives: Patients with end-stage heart failure (ESHF) treated with ventricular assist devices (VADs) tend to gain weight after implantation, which is associated with higher complication rates and is a contraindication for heart transplantation (HT). The objective was to analyze the outcomes of obese patients with ESHF and VADs who underwent laparoscopic sleeve gastrectomy (LSG) at Ochsner Medical Center in New Orleans, which is the only program performing VADs and HT in the State of Louisiana, and also one of the largest VAD centers in the USA.

Data description: This dataset contains detailed baseline, perioperative, and long-term data of patients with VADs undergoing LSG. These variables were collected retrospectively from electronic medical records. Patients who achieved $\geq 50 \%$ excess BMI loss, $\mathrm{BMI} \leq 35 \mathrm{~kg} / \mathrm{m}^{2}$, listing for $\mathrm{HT}, \mathrm{HT}$, or myocardial recovery were identified and the timing to each of these milestones was documented. These data can be used alone or in combination with other datasets to achieve a larger sample size with more power for further analysis of these variables, which include the most important, standard, and objective bariatric and ESHF outcomes of patients with VADs undergoing LSG. Elaboration of composite outcomes is feasible.
\end{abstract}

Keywords: Heart failure, Ventricular assist devices, Heart-assist devices, Bariatric surgery, Laparoscopic sleeve gastrectomy, Weight loss, Body mass index, Heart transplantation, Metabolism, Echocardiography

\section{Objective}

The use of ventricular assist devices (VADs) in patients with end-stage heart failure (ESHF) has grown significantly over the last decade. Nowadays, many patients undergo VAD implantation as a bridge to heart transplantation (HT), and remain on VAD support while awaiting availability of a healthy compatible heart. In other cases, patients undergo VAD implantation after being rejected for HT due to significant obesity $\left(\mathrm{BMI} \geq 35 \mathrm{~kg} / \mathrm{m}^{2}\right)$ [1].

\footnotetext{
*Correspondence: adrianjdasilva@gmail.com

${ }^{1}$ The John Ochsner Heart and Vascular Institute, Ochsner Clinic Foundation, New Orleans, LA, USA

Full list of author information is available at the end of the article
}

After VAD implantation, patients tend to feel better with appetite improvement, leading to increased caloric intake. Although exercise tolerance often improves too, it remains limited when compared to healthy subjects [2]. These factors, in addition to other comorbidities like depression, lead to weight gain after VAD implantation, especially in those patients with $\mathrm{BMI}<35 \mathrm{~kg} / \mathrm{m}^{2}$ [3]. The latter situation could lead to many obese patients with VADs as bridge to HT being deemed unsuitable candidates once they reach a $\mathrm{BMI} \geq 35 \mathrm{~kg} / \mathrm{m}^{2}$. Furthermore, obesity among patients with VADs has been associated with higher complication rates [4].

Bariatric surgery is an option for patients with VADs to lose weight and improve HT candidacy, with some

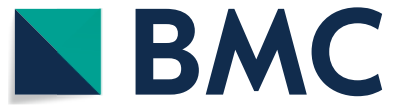

(c) The Author(s) 2020. This article is licensed under a Creative Commons Attribution 4.0 International License, which permits use, sharing, adaptation, distribution and reproduction in any medium or format, as long as you give appropriate credit to the original author(s) and the source, provide a link to the Creative Commons licence, and indicate if changes were made. The images or other third party material in this article are included in the article's Creative Commons licence, unless indicated otherwise in a credit line to the material. If material is not included in the article's Creative Commons licence and your intended use is not permitted by statutory regulation or exceeds the permitted use, you will need to obtain permission directly from the copyright holder. To view a copy of this licence, visit http://creativeco mmons.org/licenses/by/4.0/. The Creative Commons Public Domain Dedication waiver (http://creativecommons.org/publicdomain/ zero/1.0/) applies to the data made available in this article, unless otherwise stated in a credit line to the data. 
studies reporting promising results [5-7]. Over the last years, laparoscopic sleeve gastrectomy (LSG) has become the preferred bariatric surgery for obese patients with VADs due to its effectiveness and safety profile [8]. However, postoperative complications may be more common in these patients due to their need for chronic anticoagulation and comorbidities.

The objective was to analyze the outcomes of obese patients with ESHF and VADs who underwent LSG at Ochsner Medical Center in New Orleans, the only VAD and HT program in the State of Louisiana, and also one of the largest VAD centers in the USA. This dataset was used in a study submitted for publication somewhere else [9].

\section{Data description}

These data were collected retrospectively from the electronic medical records of obese patients with ESHF who underwent LSG at Ochsner Medical Center in New Orleans. All 8 patients were 18 years or older (Table 1)

Baseline variables include demographics, VAD type, anthropometric parameters (BMI, excess BMI, percentage of excess BMI, weight at VAD implantation and LSG, etc.), echocardiographic parameters of left and right ventricular functions, New York Heart Association Functional Class (NYHA FC), and blood test variables, including B-natriuretic peptide, lactate dehydrogenase, and fasting lipid panel data.

Anthropometric data were also obtained at multiple timepoints during follow-up. Postoperative echocardiographic data correspond approximately to 6 months after LSG, while blood test and NYHA FC data were collected around the 3-month follow-up. Almost all data were obtained during euvolemic state (compensated ESHF), except for the postoperative NYHA FC data of patient 8, who had a mild ESHF decompensation.

Perioperative coagulation data were collected, including the most recent international normalized ratio (INR) and partial thromboplastin time (PTT) prior to LSG, the highest INR and PTT during the 48 h post-LSG, postoperative transfusions, hospital length of stay, intensive care unit length of stay, and multiple adverse outcomes. The numbers of hospital admissions and of hospitalization days for the 6-month periods prior to and after LSG, respectively, were also collected.
Patients who achieved $\geq 50 \%$ excess BMI loss, $\mathrm{BMI} \leq 35 \mathrm{~kg} / \mathrm{m}^{2}$ (appropriate BMI for HT), listing for HT, HT, or myocardial recovery were identified and timing to each of these milestones was documented. A decrease of $50 \%$ of excess $\mathrm{BMI}$ is conventionally considered a successful outcome after LSG, while the other outcomes are of major relevance from an ESHF and HT standpoint.

Data files 1 and 2 contain the complete dataset and a description of each variable, respectively. These data show the most important outcomes and efficacy of LSG in obese patients with VADs to improve their candidacy for HT as well as other major bariatric and ESHF parameters.

In patients with VADs, LSG is only performed in carefully selected patients in few centers for ESHF and HT. Hence, the sample sizes of published studies in this topic range from 1 to 11 patients $[5,10]$. These data can be combined with other datasets to create multicenter cohorts to increase power and external validity of future studies evaluating the effects of LSG on BMI/weight loss, echocardiographic, functional, metabolic, and more importantly, ESHF outcomes such as listing for HT, HT, and myocardial recovery. The objective and standard definition of these variables across studies, and their relevance for clinical management, make dataset combinations feasible, even for comparing outcomes between patients with VADs undergoing LSG vs. patients who receive VAD implantation and LSG simultaneously.

Future studies could analyze composite outcomes including reaching a $\mathrm{BMI} \leq 35 \mathrm{~kg} / \mathrm{m}^{2}$, which is indicative of enough decrease in BMI as to improve their candidacy for HT, in combination with traditional ESHF outcomes such as listing for HT, HT, or myocardial recovery. Additionally, adverse events and other negative outcomes could also be analyzed as composite.

\section{Limitations}

This is a single-center database, hence, the generalizability of the information it provides should be interpreted cautiously, and attention should be paid to the baseline characteristics and perioperative management, which has been described above and in the original research study published by our team using this dataset.

Although this is one of the largest datasets of obese patients with VADs who have undergone any bariatric

Table 1 Overview of data files/datasets

\begin{tabular}{|c|c|c|c|}
\hline Label & Name of data file/data set & $\begin{array}{l}\text { File types (file } \\
\text { extension) }\end{array}$ & Data repository and identifier (DOI or accession number) \\
\hline Data file 1 & Database LSG in patients with VADs & xlsx (or Excel) & Mendeley https://dx.doi.org/10.17632/8s35tzr33g.2 \\
\hline Data file 2 & Description of variables & xlsx (or Excel) & Mendeley https://dx.doi.org/10.17632/8s35tzr33g.2 \\
\hline
\end{tabular}


surgery, its sample size is not large enough to allow for more advanced inferential statistical analysis such as regressions. However, considering that bariatric and ESHF outcomes are very standard among studies, it is feasible to combine this dataset with other single or multicenter samples to achieve a higher statistical power for more advanced statistical tests that would allow to identify predictors of successful and poor outcomes, which will help to guide clinical practice and improve quality of care for these complex patients with delicate health.

\section{Abbreviations}

BMI: Body mass index; ESHF: End-stage heart failure; $\mathrm{HT}$ : Heart transplantation; INR: International normalized ratio; LSG: Laparoscopic sleeve gastrectomy; NYHA FC: New York Heart Association functional class; PTT: Partial thromboplastin time; VAD: Ventricular assist device.

\section{Acknowledgements}

This article is part of the doctoral research thesis of Adrian daSilva-deAbreu, who is the principal investigator of this study and main author of this paper. All other authors commit to not using this publication as main part of their doctoral theses. However, this does not mean that this article cannot be used by the other authors as complement merit in their doctoral theses.

\section{Authors' contributions}

AdS-dA, BAA, and KG contributed with study design, data gathering, data processing, as well as manuscript drafting and editing. SD, CE, SK, HP, CJL, HOV, JFL-F, and SAM contributed with supervision of the study, and manuscript editing. All authors read and approved the final manuscript.

\section{Funding}

None.

\section{Availability of data and materials}

The data described in this Data note can be freely and openly accessed on Mendeley Data under https://doi.org/10.17632/8s35tzr33g.2. Please see Table 1 and Refs. $[9,11]$ for details.

\section{Ethics approval and consent to participate}

This project was approved by the Institutional Review Board (Study \# 2019.410) of the Ochsner Medical Center, New Orleans, LA, USA. This study was exempted of signed consent from patients given its retrospective design. This raw data has not been published in any other article.

\section{Consent for publication}

Not applicable.

\section{Competing interests}

SAM is a paid speaker for United Therapeutics Corporation and Bayer. All other authors declare no conflicts of interest related to this study.

\section{Author details}

${ }^{1}$ The John Ochsner Heart and Vascular Institute, Ochsner Clinic Foundation, New Orleans, LA, USA. ${ }^{2}$ Ochsner Clinical School, Faculty of Medicine,
The University of Queensland, New Orleans, LA, USA. ${ }^{3}$ Doctoral School, Universidad de Las Palmas de Gran Canaria, Las Palmas, Spain. ${ }^{4}$ Department of Internal Medicine, The Ohio State University, Columbus, OH, USA.

Received: 18 July 2020 Accepted: 4 September 2020

Published online: 17 September 2020

\section{References}

1. Mehra MR, Canter CE, Hannan MM, et al. The 2016 International Society for Heart Lung Transplantation listing criteria for heart transplantation: a 10-year update. J Heart Lung Transplant. 2016;35(1):1-23.

2. Adamopoulos S, Corrà U, Laoutaris ID, et al. Exercise training in patients with ventricular assist devices: a review of the evidence and practical advice. A position paper from the Committee on Exercise Physiology and Training and the Committee of Advanced Heart Failure of the Heart Failure Association of the European Society of Cardiology. Eur J Heart Fail. 2019:21(1):3-13.

3. Jaiswal A, Truby LK, Chichra A, et al. Impact of obesity on ventricular assist device outcomes. J Card Fail. 2020;26(4):287-97.

4. Clerkin KJ, Naka Y, Mancini DM, et al. The impact of obesity on patients bridged to transplantation with continuous-flow left ventricular assist devices. JACC Heart Fail. 2016;4(10):761-8.

5. Hawkins RB, Go K, Raymond SL, et al. Laparoscopic sleeve gastrectomy in patients with heart failure and left ventricular assist devices as a bridge to transplant. Surg Obes Relat Dis. 2018;14(9):1269-73.

6. Morrow EH, Pellegrini CA, Mokadam NA, et al. Laparoscopic gastric bypass during left ventricular assist device support and ventricular recovery. J Heart Lung Transplant. 2014;33(8):870-1.

7. Punchai S, Nor Hanipah Z, Sharma G, et al. Laparoscopic sleeve gastrectomy in heart failure patients with left ventricular assist device. Obes Surg. 2019;29(4):1122-9.

8. Shah SK, Gregoric ID, Nathan SS, et al. Simultaneous left ventricular assist device placement and laparoscopic sleeve gastrectomy as a bridge to transplant for morbidly obese patients with severe heart failure. J Heart Lung Transplant. 2015;34(11):1489-91.

9. daSilva-deAbreu A, Garikapati K, Alhafez BA, et al. Laparoscopic sleeve gastrectomy in patients with obesity and ventricular assist devices: a comprehensive outcome analysis. Obes Surg. 2020. https://doi. org/10.1007/s11695-020-04948-9.

10. Lockard KL, Allen C, Lohmann D, et al. Bariatric surgery for a patient with a HeartMate II ventricular assist device for destination therapy. Prog Transplant. 2013;23(1):28-322.

11. daSilva-deAbreu A, Garikapati K, Alhafez BA, et al. Laparoscopic sleeve gastrectomy in obese patients with ventricular assist devices. Version 2. Mendeley Data. 2020. https://doi.org/10.17632/8s35tzr33g.2.

\section{Publisher's Note}

Springer Nature remains neutral with regard to jurisdictional claims in published maps and institutional affiliations.

Ready to submit your research? Choose BMC and benefit from:

- fast, convenient online submission

- thorough peer review by experienced researchers in your field

- rapid publication on acceptance

- support for research data, including large and complex data types

- gold Open Access which fosters wider collaboration and increased citations

- maximum visibility for your research: over $100 \mathrm{M}$ website views per year

At BMC, research is always in progress.

Learn more biomedcentral.com/submissions 